\title{
Student Perspectives Regarding Specialty Pharmacy Within Doctor of Pharmacy Curricula
}

\author{
Joseph P. Fava, PharmD, BCACP; Kristen M. Zofchak, PharmD; Tyler J. Jedinak, PharmD,
} and Steven R. Erickson, BSPharm, PharmD

\begin{abstract}
BACKGROUND: The rapid growth of the specialty pharmacy industry will require many pharmacists with experience and/or training in specialty pharmacy practice (SPP). Unfortunately, there is no standard requirement set forth by the Accreditation Council for Pharmacy Education (ACPE) for specialty pharmacy education among pharmacy schools, which has resulted in graduates with doctor of pharmacy degrees (PharmD) having little to no didactic or experiential training in SPP.
\end{abstract}

OBJECTIVES: To (a) assess PharmD student perspectives on coverage of specialty pharmacy in their respective curricula and (b) identify whether attitudes and perspectives towards SPP vary based on student work experience.

METHODS: Study investigators created a 16-item web-based survey that assessed student work experience in pharmacy practice, presence of learning experiences that cover SPP in PharmD curricula, and familiarity with, exposure to, and interest in SPP, SPP learning experiences, and SPP careers. The survey was made available to students at ACPE-accredited colleges of pharmacy from January to April 2018.

RESULTS: 643 students from 20 different colleges of pharmacy completed the survey. Over half of the surveys $(63.3 \%)$ originated from schools in the Midwest region of the United States. Just over one third (37.7\%) of students reported that their curricula offered a learning experience specifically dedicated to SPP, whereas $17.6 \%$ reported that SPP was integrated into other pharmacy coursework. $28 \%$ reported that SPP was covered using a mixture of dedicated courses and class integration. Students with current or previous work experience in SPP or managed care were more likely to report willingness to take an experiential rotation in SPP and pursue a career in SPP than students with no or other pharmacy-related work experience. These students were also more likely to report that their curriculum performed poorly in preparing students to pursue a career in SPP.

CONCLUSIONS: In a convenience sample survey of pharmacy students at ACPE-accredited colleges of pharmacy, perspectives on SPP, curricular coverage of SPP, and SPP careers varied significantly based on student work experience.

J Manag Care Spec Pharm. 2019;25(11):1255-59

Copyright $\odot 2019$, Academy of Managed Care Pharmacy. All rights reserved.

\section{What is already known about this subject}

Specialty pharmaceuticals currently represent almost half of the overall pharmacy benefit spend, with continued growth expected in the coming years.

The current availability of formal training in specialty pharmacy for pharmacists and pharmacy students is lacking in the pre- and postgraduate settings.

The Accreditation Council for Pharmacy Education has no specific requirements that outline how specialty pharmacy should be covered in doctor of pharmacy (PharmD) curricula.

\section{What this study adds}

This study displays PharmD student perception of how specialty pharmacy practice is covered in PharmD curricula.

More positive attitudes and perceptions toward specialty pharmacy were noted in students with work experience in specialty or managed care pharmacy compared with students with no or other types of pharmacy-related work experience.

This study supports the need for more comprehensive specialty pharmacy education, which may improve student attitudes and perceptions toward training and careers in specialty pharmacy practice.
W ith recent advances in health care sciences, including a focus on biologics and personalized medicine, specialty pharmacy has become one of the most rapidly growing aspects of pharmacy practice to date. ${ }^{1}$ Currently occupying 39\% of the overall pharmacy benefit spend, and expected to approach $50 \%$ by $2020,{ }^{2}$ health care organizations, pharmacies, and third-party payers have begun investing significant resources into the procurement and handling of specialty pharmaceuticals, including counseling, monitoring, and follow-up for patients taking these drugs, to maximize safety and efficacy in disease management. Specialty pharmacy services-which include but are not limited to prior authorization and drug utilization review navigation, drug administration education using unique delivery devices, collaborative care management to address adverse drug events, side effects, nonadherence, and Risk Evaluation and Mitigation Strategies program management-require specialized training beyond that of basic pharmacotherapeutics. Thus, there is a 
critical need for pharmacists to develop the skills necessary to practice in this facet of pharmacy.

Specialty pharmacy and/or training in specialty pharmacy practice (SPP) is not specifically mentioned as an educational requirement or standard in the 2016 Accreditation Council for Pharmacy Education (ACPE) Accreditation Standards and Key Elements for the Professional Program in Pharmacy Leading to the Doctor of Pharmacy Degree. ${ }^{3}$ Hence, colleges of pharmacy are not held to a specific standard that regulates when and how pharmacy students are trained in or gain exposure to SPP. At the rate specialty pharmacy is expanding, however, it is crucial that we identify if and how pharmacy students are being trained in this field.

The goal of this study was to assess the perspectives of doctor of pharmacy (PharmD) students on coverage of specialty pharmacy in their respective curricula and identify whether attitudes and perspectives towards SPP vary based on student work experience.

\section{Methods}

A list of ACPE-accredited colleges of pharmacy was obtained from the ACPE website (https://www.acpe-accredit.org/accredited-programs-by-status/). Only fully accredited colleges were invited to take the survey (colleges in "candidate" or "precandidate" status were excluded). Investigators contacted each school's academic service officer (ASO) via email, requesting that the survey be distributed among the school's students. ASOs were identified by searching each school's website. If an ASO was not identified, the investigators contacted a different faculty or staff member with student affairs identified as one of their roles (e.g., student affairs coordinator or associate dean of student affairs). If no response was received from the ASO/ contact person after the first communication or if no survey respondents from the schools were recorded after the initial contact, the investigators sent the ASO/contact person a second email. The email included a link to the web-based survey that was available for completion from January 3 to April 24, 2018.

\section{Survey Description}

The 16-item survey consisted of quantitative (multiple choice and 5-point Likert Scale questions) and qualitative (textboxenabled fillable answers as options within multiple-choice questions) measures. Questions were intended to measure respondent work experience (as a pharmacy technician, intern, or other) in pharmacy practice, as well as their perceptions of the presence of learning experiences (didactic courses, experiential rotations, or other) that covered SPP in their PharmD curricula. Further questions assessed their familiarity with, exposure to, and interest in SPP, SPP learning experiences, SPP work environments, and careers. Work experience in pharmacy practice was listed as a "choose all that apply" question that included inpatient/hospital pharmacy, community/ outpatient pharmacy, ambulatory care, managed care, specialty pharmacy, industry, other (free-text enabled), and none of the above. After responses were received, investigators categorized student work experience into 3 subsets: "standard" (representing inpatient/hospital pharmacy, community/outpatient pharmacy, ambulatory care, and/or other); "specialty and/or managed care pharmacy"; and "none." Additional information obtained from respondents included the school in which they were currently enrolled and the professional year they were currently in.

\section{Analysis}

Survey data were analyzed using SPSS statistical analysis software, version 24.0 (IBM, Armonk, NY). The unit of reference for this study was the respondent/student. Therefore, the analysis was based on the experiences afforded to students by either the pharmacy curricula or programs they were attending and/or work experience in specialty pharmacy intern or technician positions. Chi-square tests were used to describe associations between independent and dependent study variables. A $P$ value of less than 0.05 was considered significant. The study protocol was reviewed by the Wayne State University Institutional Review Board, which found it to qualify for medical exemption.

\section{Results}

\section{Demographics and Specialty Pharmacy Experiences}

A total of 643 students from 20 different ACPE-accredited colleges of pharmacy completed the survey during the study period (response rate $18.9 \%$ by school; $1 \%$ by total PharmD students enrolled in ACPE-accredited schools as of the 2017 fall semester). ${ }^{4}$ The majority of surveys originated from schools in the Midwest region of the United States (59.7\%), followed by the South (26.7\%), Northeast (7.6\%), and West (0.3\%) regions (U.S. Census Bureau Census Regions, 2015). The survey population represented a relatively even distribution of first-, second-, third-, and fourth-year students. Many students reported having had work experience in the standard subset (85.7\%), followed by specialty and/or managed care pharmacy (12.1\%). Fifty-seven (8.9\%) respondents reported having no pharmacyrelated work experience (Table 1).

According to survey responses, students perceived SPP to be covered in a variety of different ways in pharmacy curricula. Over a third (34.7\%) of respondents reported that their curricula has at least 1 learning experience dedicated to SPP (required or elective courses and/or experiential rotations); $16.2 \%$ reported that SPP was not a dedicated course or rotation, but was a topic integrated into class sessions in therapeutics, social administrative sciences, and/or practice-based courses; $25.8 \%$ of respondents reported that SPP was covered using a mixture of dedicated courses and class integration; $8.6 \%$ of respondents selected "no specialty pharmacy learning experience is offered in my curriculum"; and $4 \%$ of respondents 


\begin{tabular}{|c|c|}
\hline $\begin{array}{cl}\text { TABLE } 1) & \begin{array}{l}\text { Demographic C } \\
\text { Respondents }\end{array}\end{array}$ & es of Survey \\
\hline Surveys Completed & $\mathrm{N}=643$ \\
\hline School location (U.S. Census region) & $\mathrm{n}(\%)^{\mathrm{a}}$ \\
\hline Midwest & $384(59.7)$ \\
\hline South & $172(26.7)$ \\
\hline Northeast & $49(7.6)$ \\
\hline West & $2(0.3)$ \\
\hline Student rank & $\mathrm{n}(\%)^{\mathrm{a}}$ \\
\hline First year $(\mathrm{Pl})$ & $165(25.7)$ \\
\hline Second year (P2) & $154(24.0)$ \\
\hline Third year (P3) & $166(25.8)$ \\
\hline Fourth year (P4) & $131(20.4)$ \\
\hline Work experience & n (\%) \\
\hline Standard & $551(85.7)$ \\
\hline Specialty and/or managed care pharmacy & $78(12.1)$ \\
\hline None & $57(8.9)$ \\
\hline $\begin{array}{l}\text { aNumber and percentages may not equate to to } \\
\text { due to missing survey data. } \\
\text { bNumber and percentages may not equate to to } \\
\text { to missing survey data and/or multiple response } \\
\text { option on these survey items). }\end{array}$ & $\begin{array}{l}\text { rveys completed } \\
\text { rveys completed due } \\
\text { at apply" was an }\end{array}$ \\
\hline
\end{tabular}

selected "other" and entered free text indicating that they were not sure or did not know. Finally, 2.8\% reported that SPP was covered some other way in their curriculum, with free-text entries including reference to extracurricular seminars or guest speakers, class projects, convocations, and integration into a biochemistry course.

\section{Student Familiarity and Attitudes Toward SPP Based on Curricular Method of SPP Education}

We compared familiarity and attitudes toward SPP among respondents with how SPP was covered educationally in their curriculum. Most students (68.7\%) with dedicated SPP learning experiences and integrated class sessions in SPP in their curriculum reported familiarity with SPP, compared with $58.7 \%$ of those with integrated class sessions only, $47.1 \%$ of those with dedicated learning experiences only, and $36.4 \%$ among those who reported that their curriculum did not include any type of SPP education $(P<0.001)$. Those with dedicated SPP learning experiences and integrated class sessions in SPP in their curriculum also reported the highest willingness to look into SPP as a potential career path at $61.8 \%$, compared with $55.9 \%$ of those with integrated class sessions only, $50.7 \%$ of those with dedicated learning experiences only, and $46.0 \%$ among those who reported that their curriculum did not include any type of SPP education $(P=0.024)$.

\section{Student Perceptions Based on Work Experience}

Table 2 displays respondent familiarity with SPP, willingness to partake in SPP-focused experiential rotations, intent to pursue a career in SPP, and perception of how well SPP is covered in pharmacy curricula, based on work experience subset. Overall, $52.9 \%$ of student respondents indicated they were familiar with the concept of SPP, while $47.1 \%$ indicated they were not. Based on work experience, $85.9 \%$ of respondents with work experience in specialty and/or managed care pharmacy reported being familiar with SPP, as indicated by a selection of 3 ("fairly familiar"), 4, or 5 ("very familiar") on a 5-point Likert scale. Less than half (49.7\%) of respondents with standard pharmacy work experience, and just over a third $(33.9 \%)$ of those with no pharmacy work experience, reported being familiar with SPP $(P<0.001)$.

When asked whether students would be willing to partake in an SPP-focused experiential rotation (introductory [IPPE] or advanced [APPE] pharmacy practice experience), 33.9\% indicated that they would; $48.1 \%$ said "no"; and $18 \%$ were unsure. Based on previous or current work experience, $59.6 \%$ of those with specialty and/or managed care pharmacy experience chose "yes," while $28.8 \%$ of those with standard work experience said "yes" and only $11.1 \%$ of those with no work experience indicated they would $(P<0.001)$.

When asked whether students intended on pursuing a career in SPP, $11.2 \%$ indicated they were; $22.6 \%$ indicated they were not; and $66.2 \%$ indicated they were not sure. There was a significant difference $(P<0.001)$ in the proportion of students indicating that they intend to pursue a career in SPP based on their current year in their program, with $4.1 \%$ of $\mathrm{Pl}$ students saying "no"; $13.9 \%$ of P2 students saying "no"; $30.0 \%$ of P3 students saying "no"; and $46.0 \%$ of P4 students saying "no". The change came from students moving from the "not sure" response to the "no" response. For P1 students, $80.8 \%$ indicated "not sure"; $75.5 \%$ of P2 students said "not sure"; $61.3 \%$ of P3 students said "not sure"; and $41.5 \%$ of P4 students chose "not sure."

Based on work experience, the highest proportion of respondents with standard work experience reported no intent to pursue a career in SPP at 25.3\%, compared with $14.5 \%$ of those with no pharmacy-related work experience and $13.0 \%$ of those with specialty and/or managed care pharmacy work experience $(P<0.001)$. Although the majority of students reported that they were "not sure" whether they intended to pursue a career in specialty pharmacy, the highest proportion of students who reported "yes" were those with specialty and/or managed care pharmacy work experience (28.6\%), followed by $10.9 \%$ of those with no work experience and $8.3 \%$ of those with standard work experience $(P<0.001)$.

When students indicated how well they felt their curriculum prepared them for a career in SPP, 56.7\% chose responses ranging from "fairly well" to "very well." When this value was evaluated based on student work experience, the majority of respondents with no pharmacy-related work experience $(72.7 \%)$ felt their curriculum prepared them "fairly well" or better (response of 3 ["fairly well"], 4, or 5 ["very well"] on a 


\begin{tabular}{|c|c|c|c|c|c|}
\hline & \multirow[b]{2}{*}{$\begin{array}{l}\text { Total } \\
\text { n (\%) }\end{array}$} & \multicolumn{4}{|c|}{ Work Experience } \\
\hline & & $\begin{array}{l}\text { None } \\
\text { n (\%) }\end{array}$ & $\begin{array}{l}\text { Standard } \\
\text { n (\%) }\end{array}$ & $\begin{array}{l}\text { Specialty and/ } \\
\text { or Managed Care } \\
\text { Pharmacy } \\
\text { n (\%) }\end{array}$ & $P$ Value \\
\hline \multicolumn{6}{|l|}{ How familiar are you with SPP? } \\
\hline Not familiar & $280 \quad(47.1)$ & $37 \quad(66.1)$ & $232(50.3)$ & $11 \quad(14.1)$ & \multirow{2}{*}{$<0.001$} \\
\hline Familiar & $315(52.9)$ & $19(33.9)$ & $229(49.7)$ & $67(85.9)$ & \\
\hline \multicolumn{6}{|c|}{ If your school offers a specialty pharmacy-focused IPPE or APPE, are you planning on, or are you currently taking part, in this rotation? } \\
\hline Yes & $96 \quad(33.9)$ & $1 \quad(11.1)$ & $64(28.8)$ & $31 \quad(59.6)$ & \multirow{3}{*}{$<0.001$} \\
\hline No & $136(48.1)$ & $5(55.6)$ & $118(53.2)$ & $13(25.0)$ & \\
\hline Not sure & $51(18.0)$ & $3(33.3)$ & $40 \quad(18.0)$ & $8(15.4)$ & \\
\hline \multicolumn{6}{|l|}{ Do you intend to pursue a career in specialty pharmacy? } \\
\hline Yes & $65 \quad(11.2)$ & $6 \quad(10.9)$ & $37 \quad(8.3)$ & $22(28.6)$ & \multirow{3}{*}{$<0.001$} \\
\hline No & $131(22.6)$ & $8 \quad(14.5)$ & $113(25.3)$ & $10 \quad(13.0)$ & \\
\hline Not sure & $383(66.2)$ & $41 \quad(74.5)$ & $297(66.4)$ & $45 \quad(58.4)$ & \\
\hline \multicolumn{6}{|c|}{ How well do you feel your college of pharmacy curriculum is preparing you to pursue a career in specialty pharmacy? } \\
\hline Poorly (1 or 2 on 5-point Likert scale) & $192(43.3)$ & $12(27.3)$ & $146 \quad(44.0)$ & $34(50.7)$ & \multirow{2}{*}{0.046} \\
\hline Fairly well to very well $(3,4$, or 5 on 5 -point Likert scale) & $251(56.7)$ & $32(72.7)$ & $186(56.0)$ & 33 (49.3) & \\
\hline
\end{tabular}

5-point Likert scale). Conversely, slightly over 50\% of those with specialty and/or managed care pharmacy work experience reported that their curriculum did not prepare them well for a career in SPP (response of 1 ["poorly"] or 2 on the same scale; $P=0.046)$. With regard to curricular coverage of SPP, the highest proportion of students who reported dedicated learning experiences and integrated class sessions in their curricula chose "fairly well" to "very well" at $70.9 \%$, compared with $52.7 \%$ of those who reported dedicated learning experiences only and only $25.7 \%$ in those who reported that there were no SPP learning experiences in their curriculum.

\section{Discussion}

In searching the literature for similar works, we found some comparable studies. Pittenger et al. (2010) reported that at 1 pharmacy school, most students felt uninformed about managed care pharmacy and perceived their level of education on pharmacy benefit managers to be inadequate. ${ }^{5}$ Of note, pharmacy educators have published studies that outline template frameworks for the integration of managed care and specialty pharmacy education in PharmD curricula. ${ }^{6,7}$ One of these studies displayed an increase in student knowledge of specialty pharmacy with the implementation of an elective course focused on SPP. ${ }^{7}$ However, our work is the only study to our knowledge that assesses student perspectives towards curricular coverage of SPP in PharmD programs and attitudes and perspectives towards SPP based on student work experience.

As expected, students with previous work experience in specialty pharmacy and/or managed care pharmacy reported a high familiarity with SPP, in comparison with work experience in other settings or none whatsoever. In addition, intent to take SPP-focused clinical rotations and to pursue a career in SPP were more commonly seen in those with work experience in the field. We hypothesize that this may be reflective of students basing their career interests on what they know best, what they have the most experience in, and, possibly, what they are most comfortable with.

Over half of students surveyed who reported work experience in managed care and/or specialty pharmacy settings felt that their curriculum prepared them poorly for a career in specialty pharmacy. This may be a result of specific skills and knowledge attained from practicing in these fields that were not provided to them during their pharmacy education. On the other hand, over half of students surveyed who reported standard work experience felt that their pharmacy curriculum did "fairly well" to "well" in preparing them for specialty pharmacy careers. This may be due to the lack of understanding (in these students) of exactly what knowledge and skills are necessary for specialty pharmacy positions.

\section{Limitations}

Our study should be interpreted with several limitations. First, because this is a convenience sample survey, recruitment of participants resulted in a respondent population most largely represented by schools in the Midwest, in comparison with other regions. A possible explanation for this may include increased ASO familiarity with the institution conducting the survey, which is also located in the Midwest (Detroit, MI). Second, our survey response rate represented less than 20\% of ACPE-accredited schools and only $1 \%$ of total PharmD stu- 
dents at these schools. Twenty-four schools did not have ASO email addresses or other student affairs faculty/staff listed on their website and so were not contacted. This situation could have been mitigated by contacting different faculty/staff or calling the schools directly. In addition, others either did not respond to our contact attempts or did not disclose whether they disseminated the survey to their student bodies.

The small sample size obtained restricted the ability to use multivariate analyses to compare results based on a larger number of variables, such as school-specific responses, geographic location of schools, student ranking, and several others. The small sample size also limited external validity. However, this study does offer a unique look into student perspectives and attitudes toward SPP and reveals a potential need for higher quantity and better quality SPP education in PharmD curricula.

\section{Conclusions}

In a survey of PharmD students at ACPE-accredited colleges of pharmacy, we found student perceptions of curricular SPP coverage to be highly variable. Students with previous work experience in specialty pharmacy and/or managed care pharmacy reported more familiarity with SPP and more willingness to pursue experiential training and career opportunities in SPP. Most students with no pharmacy-related work experience felt that their curriculum was designed to prepare them well for careers in SPP, whereas reports from those with pharmacyrelated work experience were mixed. Future research in this area should target a larger sample size to elucidate which type of SPP education (didactic, experiential, or both) results in more comfort, competency, interest, and/or career intent for SPP among students. These results could also help determine what schools or geographic areas provide the most robust SPP education and could serve as potential models for other schools to use in curriculum development and design.

\section{Authors}

JOSEPH P. FAVA, PharmD, BCACP; KRISTEN M. ZOFCHAK, PharmD; and TYLER J. JEDINAK, PharmD, Department of Pharmacy Practice, Eugene Applebaum College of Pharmacy and Health Sciences, Wayne State University, Detroit, Michigan. STEVEN R. ERICKSON, BSPharm, PharmD, College of Pharmacy, The University of Michigan, Ann Arbor.

AUTHOR CORRESPONDENCE: Joseph P. Fava, PharmD, BCACP, Department of Pharmacy Practice, Eugene Applebaum College of Pharmacy and Health Sciences, Wayne State University, 259 Mack Ave., Ste. 2190, Detroit, MI 48201. Tel.: 313.993.7517;

E-mail: joseph.fava@wayne.edu.

\section{DISCLOSURES}

This study received funding support from the Wayne State University Department of Pharmacy Practice Research \& Development Fund. The authors do not have any conflicts of interest or financial disclosures to declare.

\section{REFERENCES}

1. Pahlavan P. Specialty pharmacy by the numbers. Specialty Pharmacy Times April 10, 2019. Available at: https://www.specialtypharmacytimes.com/news/ specialty-pharmacy-by-the-numbers. Accessed September 27, 2019.

2. James D. Specialty drugs power growth in pharmacy benefit spend. Pharmacy Times. April 23, 2018. Available at: https://www.pharmacytimes. com/news/specialty-drugs-power-growth-in-pharmacy-benefit-spend. Accessed September 27, 2019.

3. Accreditation Council for Pharmacy Education. Accreditation standards and key elements for the professional program in pharmacy leading to the doctor of pharmacy degree ("Standards 2016"). February 2, 2015. Available at: https://www.acpe-accredit.org/pdf/Standards2016FINAL.pdf. Accessed September 27, 2019

4. American Association of Colleges of Pharmacy. Profile of pharmacy students: fall 2017. Available at: https://www.aacp.org/sites/default/files/201805/fall-2017-profile\%20 of\%20pharmacy\%20students-introduction.pdf. Accessed September 27, 2019.

5. Pittenger AL, Starner CI, Thompson K, et al. Pharmacy students' views of managed care pharmacy and PBMs: should there be more exposure to managed care in the pharmacy curriculum? J Manag Care Pharm. 2010;16(5): 346-54. Available at: https://doi.org/10.18553/jmcp.2010.16.5.346.

6. Latif DA, Robinson ET. Students gain exposure to managed care principles at a new school of pharmacy. J Manag Care Pharm. 1999;5(4):371-71. Available at: https://doi.org/10.18553/jmcp.1999.5.4.371.

7. Stevenson JG, Lapointe S, Sabourin A, et al. Implementing a specialty pharmacy course within a professional pharmacy curriculum. Curr Pharm Teach Learn. 2019;11(1):106-13. Available at: https://www.sciencedirect. com/science/article/pii/S1877129718300303?via\%3Dihub. Accessed September 27, 2019 